\title{
Electrochemical Experiment to Evaluate the Impact of Multistage Load and Osmotic Pressure on Anchor Bolt
}

\author{
Guanglin Sun $\mathbb{D}^{1},{ }^{1}$ Jiangchun $\mathrm{Hu}\left(\mathbb{D},{ }^{1}\right.$ Hongfang Wang, ${ }^{2}$ and Dewei $\mathrm{Li}^{1,3}$ \\ ${ }^{1}$ School of Architecture and Civil Engineering, Zhongyuan University of Technology, Zhengzhou 450007, China \\ ${ }^{2}$ School of Materials and Chemical Engineering, Zhongyuan University of Technology, Zhengzhou 450007, China \\ ${ }^{3}$ Henan Zhenghong Property Co. Ltd., Zhengzhou 450001, China \\ Correspondence should be addressed to Jiangchun Hu; hujiangchun@126.com
}

Received 8 September 2021; Revised 6 January 2022; Accepted 26 January 2022; Published 11 February 2022

Academic Editor: Tianshou Ma

Copyright ( $) 2022$ Guanglin Sun et al. This is an open access article distributed under the Creative Commons Attribution License, which permits unrestricted use, distribution, and reproduction in any medium, provided the original work is properly cited.

In this paper, uniaxial compression tests, multistage loading tests, and electrochemical tests were adopted to investigate the strain characteristics, failure characteristics, and electrochemical impedance of anchor bolts in a cement-gypsum composite. The uniaxial compression test results showed that the uniaxial compressive strength $\sigma_{c}$ of the three specimens were $4.4 \mathrm{MPa}, 4.0 \mathrm{MPa}$, and 3.1 MPa, respectively, under three different osmotic pressures. The analysis of the multistage loading tests revealed that the directions of most cracks were approximately consistent with the load-bearing direction. Moreover, the existence of osmotic pressure increased the creep deformation capacity of the specimen; the greater the osmotic pressure, the stronger the deformation capacity of the specimen. The curvature relationship of the total strain curve of the three specimens was $\mathrm{K}_{\mathrm{S} 12}>\mathrm{K}_{\mathrm{S} 22}>\mathrm{K}_{\mathrm{S} 32}$, and the total strain curve of S32 was close to a straight line. When comparing the creep strain variation characteristics of the three specimens, it was found that, with the increase of osmotic pressure, the proportion of creep strain within the total strain gradually increased, while the proportion of corresponding elastic strain gradually decreased. Compared with the specimen before failure, the electrochemical test in the failure stage proved the variability of the Bode curves and Nyquist curves. When the osmotic pressure was $0.15 \mathrm{Mpa}$, the Bode diagram of specimen S32 in the low frequency band showed a large jump, which was stable after entering the high frequency band.

\section{Introduction}

Electrochemical impedance spectroscopy is a technique using a new multidisciplinary perspective for solving geotechnical problems that can describe the state of physical property indicators. Furthermore, this method has the benefits of high speed and convenience and is a nondestructive process in experimental testing [1]. It can be applied to the testing of contaminated soil, as confirmed by $\mathrm{He}$ et al. [2], who tested the electrochemical characteristics of quartz sand, including the Nyquist curves and Bode curves. Zhu et al. [3] analyzed the damage and corrosion of the free section of prestressed anchor rod under the conditions of acid and oxygen flow rate corrosion. Based on the experimental results, they established the electrochemical corrosion rate development model and pointed out that prestress had a great impact on the corrosion of anchor bolts.
Mundhenk et al. [4] studied the electrochemical impedance spectrum curve of carbon steel in the geothermal temperature range under the corrosion condition of a weak acidic solution and found that the experimental method of electrochemical impedance spectrum could be used to study the corrosion of geotechnical engineering. Blanco et al. [5] first doped recycled polyethylene terephthalate with different geometries in reinforced concrete and then put the specimen in sodium chloride corrosion solution for 300 days. The results of electrochemical impedance spectroscopy showed that rectangular, fiber, and rectangular mixed shapes could reduce the corrosion rate of reinforcement in concrete. Steel corrosion in concrete is a highly complex phenomenon, which can be studied through electrochemical impedance spectroscopy [6]. Under dry and wet conditions, Nishimura [7] proved using the electrochemical impedance spectroscopy test that when the chloride ion concentration in 
concrete exceeds a certain threshold, corrosion and damage will occur in steel. Tran et al. [8] employed electrochemical technology to evaluate the repair effect of reinforcement in concrete. Engblom et al. [9] studied the electrochemical monitoring of three rock samples under different conductive solution flow rates. Najimi et al. [10] used electrochemical technology to prove that the corrosion rate of the interface between steel and concrete can be significantly improved when portland cement is replaced by natural zeolite and copper slag by $30 \%$ in weight. Berrami et al. [11] discussed the influence of corrosive soil on the durability of the mortar layer of a prestressed concrete cylindrical pipe and compared the corrosion rate of two mortar layer mixtures with different components by electrochemical impedance spectroscopy. They reported that the method of adding fly ash into the mortar coating could improve the corrosion resistance of prestressed steel wire. Sohail et al. [12] evaluated the corrosion rate of different types of reinforcement in a chloride corrosion environment by electrochemical impedance spectroscopy. Through the electrochemical test of reinforced concrete specimens in chloride for 2.5 years, Nguyen et al. [13] found that the cracks caused by corrosion affected the electrochemical parameters of the specimens. For example, the cracks along the length of the reinforcement reduced the ohmic resistance of the concrete. Eid et al. [14] showed no significant difference in the influence of clay type on the corrosion rate of reinforcement. In the evaluation of corrosion rates, AC impedance spectroscopy has proved more accurate than voltammetry. Cabrera-Luna et al. [15] confirmed that the electrochemical properties of reinforced concrete have a certain correlation with the microstructure (test time of 180 days, 3.5\% NaCl). Electrochemical impedance spectroscopy was employed to predict the corrosion reaction of an anchor with time [16]. Wu et al. [17] studied the corrosion behavior of reinforcement in coral aggregate seawater concrete by electrochemical impedance spectroscopy. Shuquan et al. [18] studied sulfate saline soil using this technique, and they found that the soil electrical impedance modulus decreased with the increase of salt content and water content of saline soil. Jiang et al. [19] pointed out that compared with freshwater environment, chloride ions in saltwater can diffuse into concrete, thus reducing the resistance of the concrete pore solution, but they will not alter the mesostructure and phase angle of concrete.

However, the reinforced concrete structure in operation is prone to corrosion damage, the bonding ability between reinforcement and concrete decreases over time, and the anchor structure produces deformation, cracks, and other damage phenomena $[20,21]$. Seepage pressure has an important influence on concrete dams [22], and it is also an important factor affecting the incubation and development process, including the opening and closing of anchor cracks [23]. Feng and Zhang [24] revealed that the deviatoric stress of unsaturated soil was positively correlated with matrix suction. In the creep failure experiment of sandy mudstone, Shi et al. [25] found that compared with the uniaxial compression failure experiment, the failure surface of the creep failure specimen was more rough and irregular, and the crack path of the creep specimen was more complex. Huang et al. [26] indicated a certain nonlinear relationship between seepage and the length and width of cracks. Gao and Liu [27] conducted uniaxial and triaxial compression tests on coal samples with different moisture contents and found that the uniaxial compressive strength, elastic modulus, and Poisson's ratio of coal samples did not increase or decrease monotonically with the increase of moisture content. Peng et al. [28] tested the permeability and electrochemical impedance of calcite containing cracks, pores, and under confining pressure. Bolt anchoring technology is an indispensable reinforcement method for geotechnical engineering constructs, such as coal mine support and concrete beams [29-31], in addition to the fiber-reinforced composite material anchoring system [32]. Anchor bolts, such as those in underground engineering applications, can transfer loads, resist shear, and withstand tensile deformation and surrounding rock deformation [33, 34].

In this paper, uniaxial tests and multistage load tests were carried out to study the electrochemical characteristics of anchors under multistage load and osmotic pressure. A total of 21 electrochemical impedance spectroscopy tests were performed on three specimens. The uniaxial compression test plays a key role in determining the uniaxial compressive strength of specimens. The electrochemical measurement data under different loads and osmotic pressures could be used to characterize the changes in microstructure in the specimens. The specimens' uniaxial compressive strength $\sigma_{c}$ was measured. Then, the change process of stress-strain curves of specimens was analyzed, and the Bode diagram, as well as the Nyquist curves of specimens under multistage load and osmotic pressure, was discussed. The findings hopefully provide a basis to further understand the electrochemical properties of anchored solids.

\section{Materials and Methods}

\subsection{Test Preparation}

2.1.1. Specimen Preparation. Cement, gypsum, quartz sand, and $5 \%$ borax aqueous solutions were used, in a mass ratio of $1: 0.25: 0.25: 0.12$ to fabricate test specimen cubes sized $150 \mathrm{~mm} \times 150 \mathrm{~mm} \times 150 \mathrm{~mm}$. An anchor bolt was installed in the test specimen to provide anchoring force, and porous steel pipes were installed to produce water osmotic pressure (Figure 1). A total of 6 test specimens were fabricated for the test, which were divided into three groups: specimens S11 and S21 were assigned to the first group, S21 and S22 to the second group, and S31 and S32 to the third group. During the test, the water osmotic pressure parameters of the two specimens in each group were consistent. The conductive electrode patch was fixed on two porous steel pipes in specimens S12, S22, and S32, while the electrode patch was not arranged in specimens S11, S21, and S31.

The water pipe osmotic pressure loaded onto the test specimen can be calculated using the following formula:

$$
p=\rho_{w} g h
$$




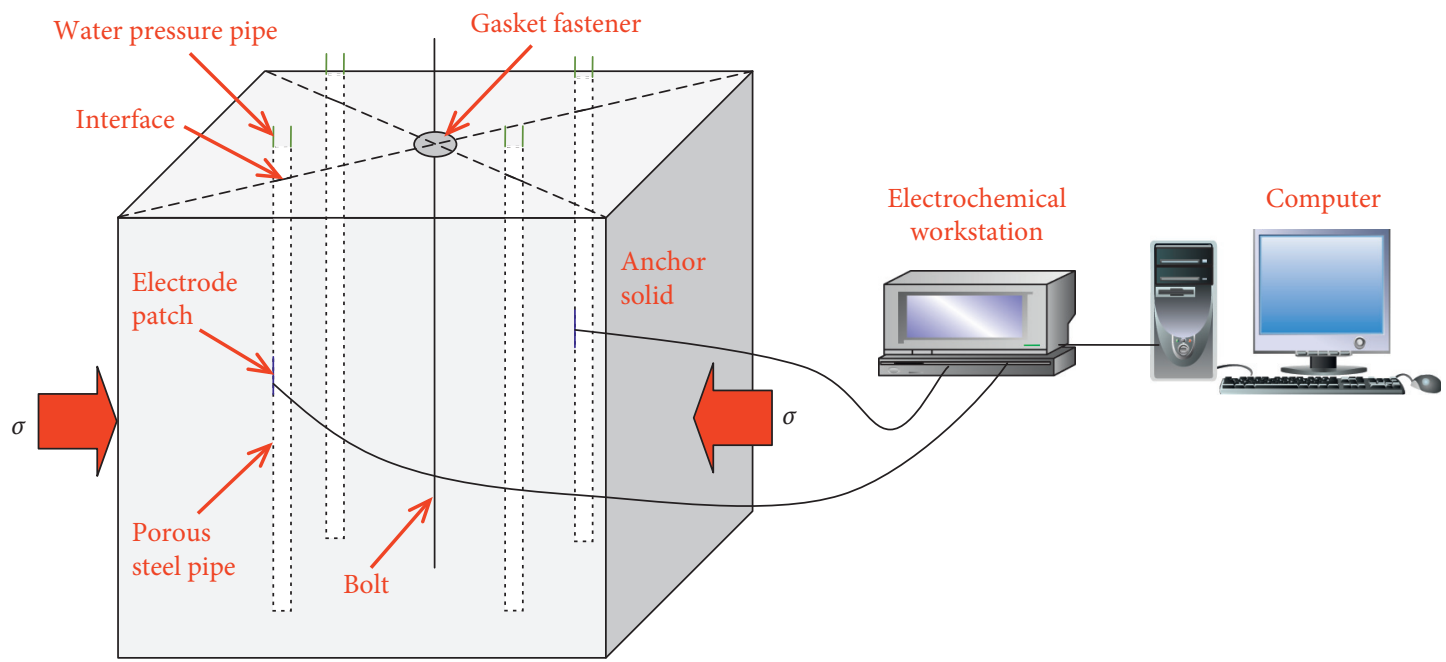

(a)

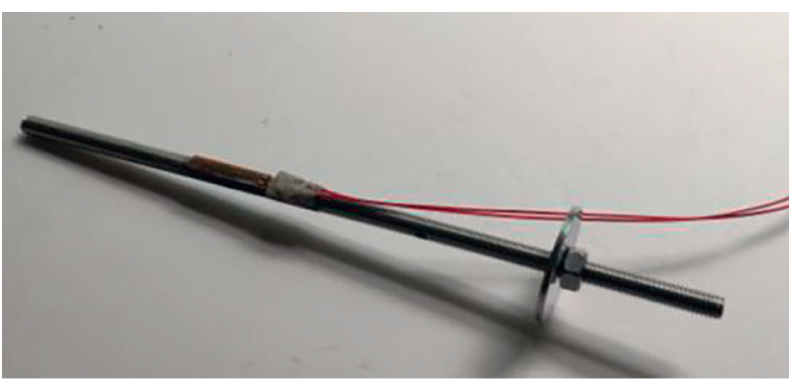

(b)

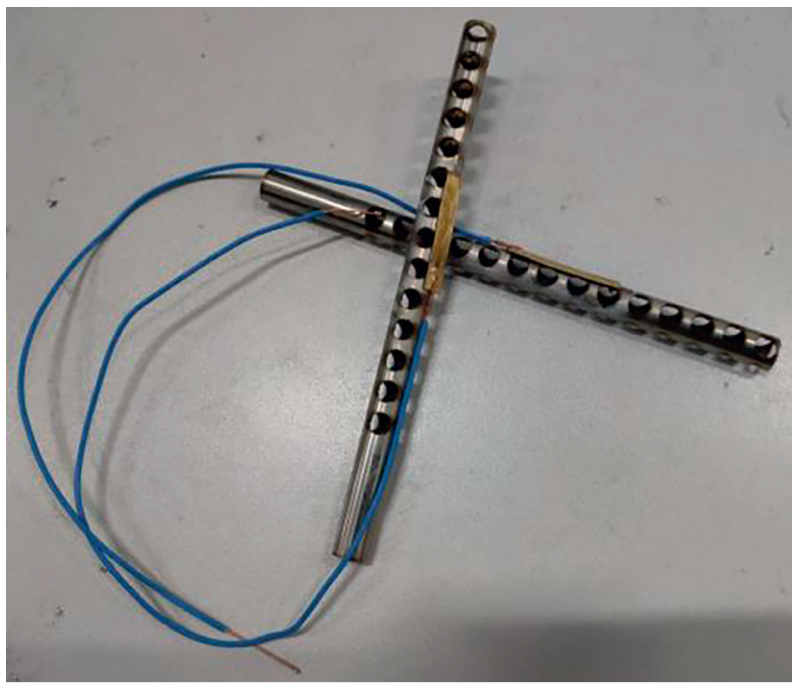

(d)

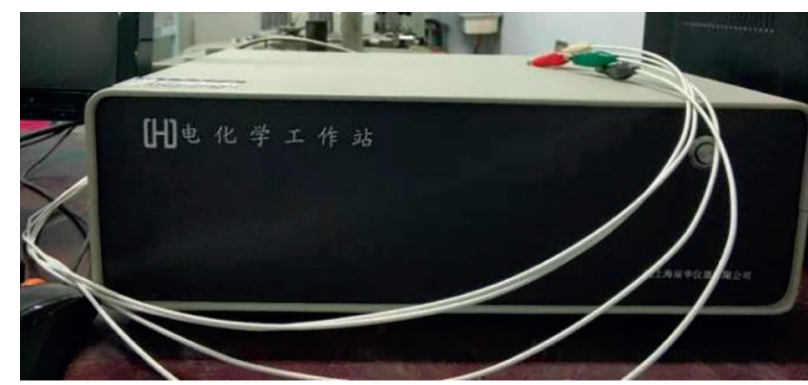

(c)

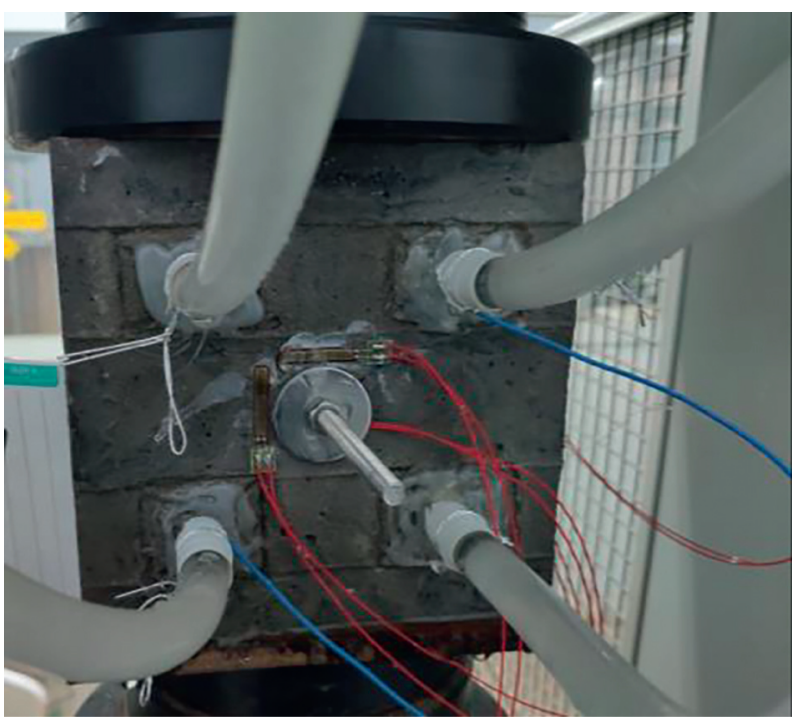

(e)

Figure 1: Schematic diagram of the test specimen: (a) schematic diagram of the experimental process; (b) bolt; (c) electrochemical workstation; (d) porous steel pipe; (e) loading diagram.

where $\rho_{w}$ represents the density of water and $\rho_{w}=$ $1 \times 10^{3} \mathrm{~kg} / \mathrm{m}^{3} ; g$ represents the gravitational constant, and $g=$ $10 \mathrm{~N} / \mathrm{kg}$; and $h$ represents the height of the water column in the water pipe. The water column heights in the water pipes used for test specimens S1, S2, and S3 were $h_{1}=5 \mathrm{~m}, h_{2}=10 \mathrm{~m}$, and $h_{3}=15 \mathrm{~m}$, respectively. Therefore, the water osmotic pressures acting on specimens $\mathrm{S} 1, \mathrm{~S} 2$, and S3 were $p_{1}=0.05 \mathrm{MPa}$, $p_{2}=0.10 \mathrm{MPa}$, and $p_{3}=0.15 \mathrm{MPa}$, respectively. 
2.1.2. Apparatus Preparation. There were two main kinds of apparatus used in the test. The first apparatus was a loading device for the uniaxial compression test and multistage loading of specimens, which was the YR-2000 model. It was set by the supporting control software named TestExpert. The second apparatus was the CHI660E electrochemical workstation (Figure 1(c)), which was used to measure the electrochemical impedance parameters of the specimen during multistage loading.

2.2. Testing Process. A uniaxial compression test was carried out on specimens S11, S21, and S31, and a multistage loading test was carried out on specimens S12, S22, and S32. The uniaxial compression test was mainly to obtain the uniaxial compressive strength of the specimens without the electrochemical test. The electrochemical test was required for the multistage loading test of specimens S12, S22, and S32. The testing process is shown in Figure 1(a). During the test, the water pressure pipe was connected to the porous steel pipe, and the pressure was provided by the water pressure generated by the water column in the water pressure pipe.

\section{Results and Discussion}

3.1. Uniaxial Compression Test. Three specimens, namely, S11, S21, and S31, were subjected to the uniaxial compression test. The stress-strain curves of each specimen are shown in Figure 2. It can be seen that, with the increase of stress, all three specimens experienced a compaction stage, an elastic stage, a crack stage, and a failure stage. The maximum stress values of the three specimens correspond to the highest points of $\mathrm{P} 1, \mathrm{P} 2$, and $\mathrm{P} 3$ in the figure, respectively. The coordinate values of these three points are P1 (4.4, 1.1), P2 (4.0, 1.9), and P3 $(3.3,1.7)$. Accordingly, the uniaxial compressive strength $\sigma_{c}$ of the three specimens was $\sigma_{c 1}=4.4 \mathrm{MPa}, \sigma_{c 2}=4.0 \mathrm{MPa}$, and $\sigma_{c 3}=3.1 \mathrm{MPa}$, respectively. In other words, the relationship between the specimens' uniaxial compressive strength values can be determined as $\sigma_{c 1}>\sigma_{c 2}>\sigma_{c 3}$. When the factors other than water pressure are the same, considering that the water pressure relationship of these specimens is $p_{1}<p_{2}<p_{3}$, we can infer that water pressure can reduce the uniaxial compressive strength of the specimens. That is, the higher the water osmotic pressure, the lower the uniaxial compressive strength.

Following the uniaxial compression test, the failure process of the three specimens was investigated and shown in Figure 3. From the figure, it can be clearly observed that many cracks appeared on the surface of the specimens. Most of the cracks run through the upper and lower loading ends, splitting the specimen into $3 \sim 6$ parts. The crack extends from the surface to the inside of the specimen. There are apparently significant internal cracks in the $\mathrm{S} 31$ specimen, as shown in Figure 3(c). The specimens had a small amount of extruded debris, and the debris amount of the three specimens is $\mathrm{S} 11<\mathrm{S} 21<\mathrm{S} 31$. Among the three specimens, the failure of S31 is the most serious one. After failure, the S31 specimen presented an inclined plane shear failure similar to

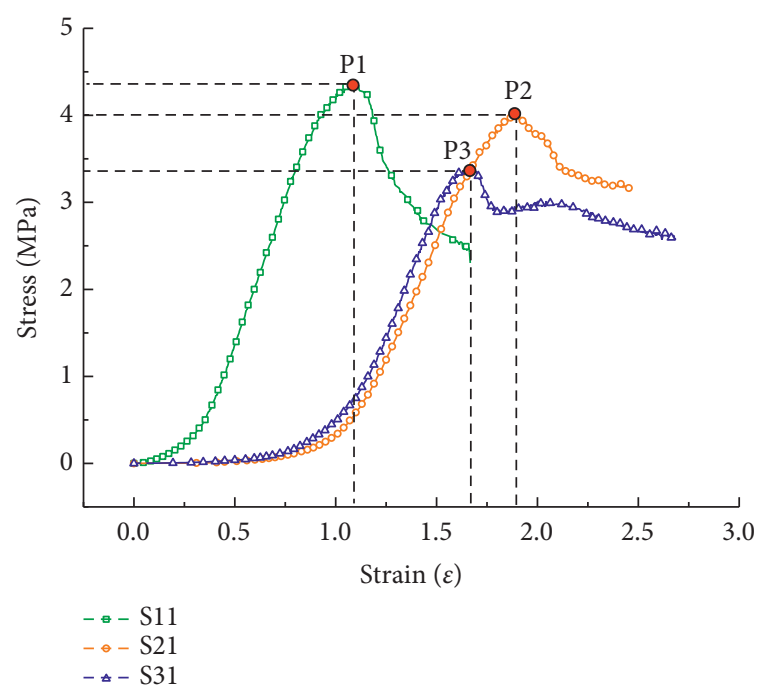

FIgURE 2: Uniaxial compressive stress-strain curves of the test specimens.

an $X$ shape. The above phenomena indicate that the greater the water osmotic pressure on the specimen, the greater the damage to the specimen.

3.2. Multistage Loading Test. Specimens S12, S22, and S32 were subjected to 6 level loading tests. Table 1 exhibits the loading values of each level. Each loading process lasted for approximately 480 minutes. The total testing time of a single specimen exceeded 2500 minutes.

The stress-strain curve of each specimen during loading is shown in Figure 4. According to the analysis of Figures 4(a) and 4(b), specimen S21 and specimen S22 were damaged in the sixth loading stage. From Figure 4(c), specimen S32 was not damaged until the end of all loading stages. In the first five constant loading stages of specimens S21 and S22, the strain of the specimen was in the process of increasing first and then gradually stabilizing. The strain characteristics of specimen S33 in the six constant loading stages also showed the same trend. In the sixth constant loading stage, the strain of specimens S31 and S32 increased sharply. Compared with the first five constant loading stages, the strain produced by specimen S33 in the sixth constant loading stage increased the most. These results demonstrate that the maximum strain produced by the specimen increased with the rise of osmotic pressure.

Figure 5 shows the crack development of the three specimens after the test. There were cracks on the surfaces of all three specimens after multistage loading, and the number of cracks was mostly $1 \sim 3$, which is less than the number of cracks generated by the specimen after the uniaxial compression test in Figure 3. The development direction of most cracks is approximately consistent with the load-bearing direction.

Figure 6 shows the total strain, elastic strain, and creep strain of the specimen. As can be seen from the figure, the total strain, elastic strain and creep strain of specimens S12, S22, and S32 all increased with the increase in the load level. 


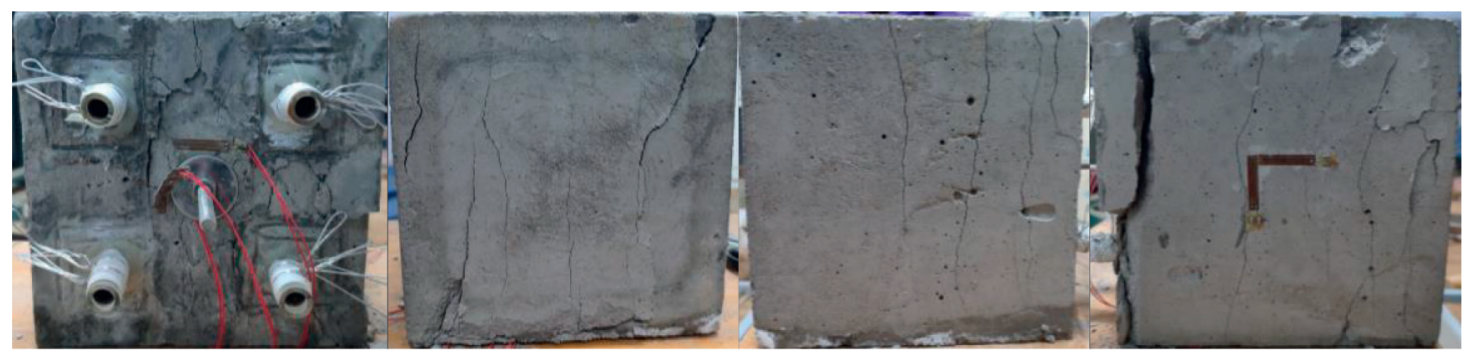

(a)

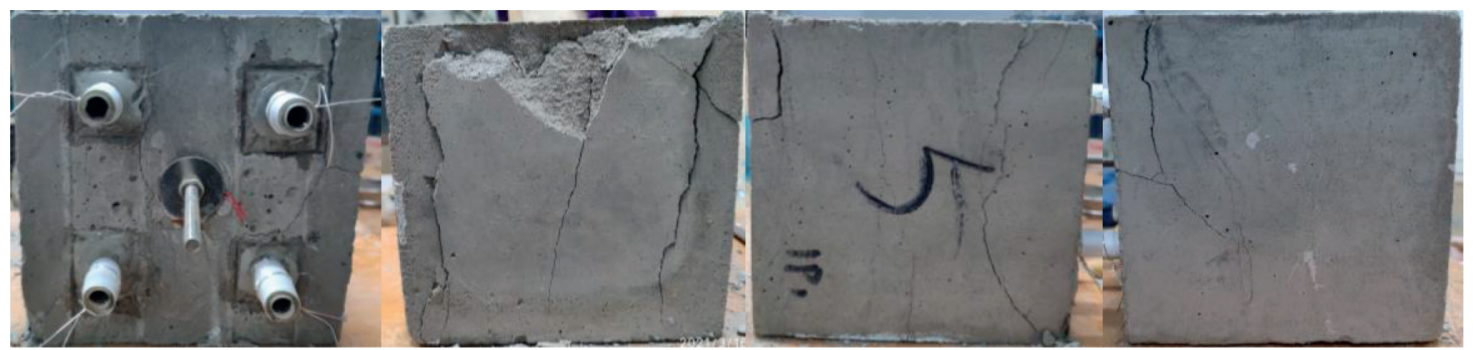

(b)

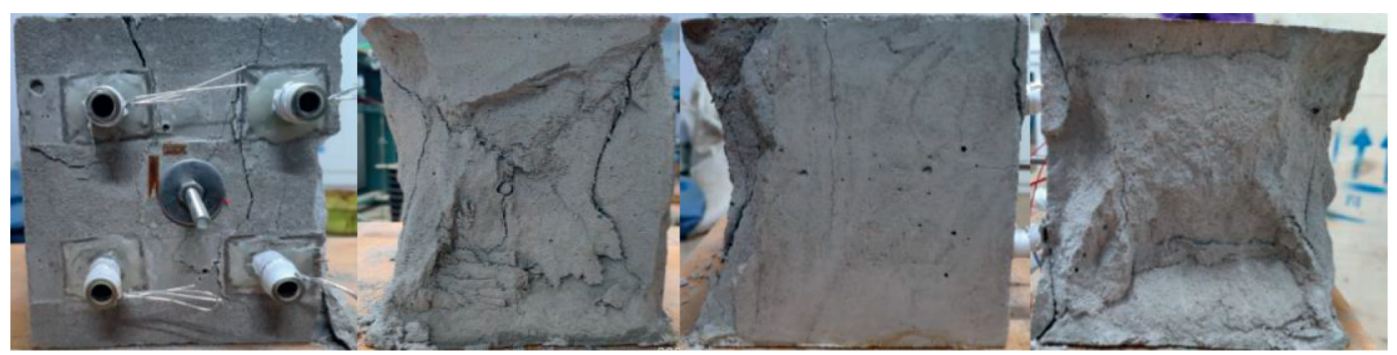

(c)

FIGURE 3: Failure of the specimens after uniaxial compression test: (a) S11; (b) S21; (c) S31.

TABLE 1: Load value of each level.

\begin{tabular}{|c|c|c|c|c|c|c|c|}
\hline \multirow{2}{*}{ Specimen } & \multicolumn{7}{|c|}{ Load value (MPa) } \\
\hline & Uniaxial compressive strength $\sigma_{c}$ & $1^{\text {st }}$ level & $2^{\text {nd }}$ level & $3^{\text {rd }}$ level & $4^{\text {th }}$ level & $5^{\text {th }}$ level & $6^{\text {th }}$ level \\
\hline S12 & 4.4 & 0.65 & 1.31 & 1.96 & 2.62 & 3.28 & 3.93 \\
\hline S22 & 4.0 & 0.60 & 1.20 & 1.81 & 2.41 & 3.01 & 3.61 \\
\hline S32 & 3.1 & 0.47 & 0.93 & 1.40 & 1.87 & 2.33 & 2.80 \\
\hline
\end{tabular}

Under each loading stage, the elastic strain of specimens S12 and S22 was greater than the creep strain. For specimen S32, the elastic strain of the first five loading stages was also greater than the creep strain, but in the sixth loading stage, the creep strain of the specimen exceeded the elastic strain. The total strain of the three specimens shows the shape of an upward convex function curve. The curvature relationship of the total strain curve of the three specimens can be described as $\mathrm{K}_{\mathrm{S} 12}>\mathrm{K}_{\mathrm{S} 22}>\mathrm{K}_{\mathrm{S} 32}$, and the total strain curve of S32 is closer to a straight line. The elastic strain of the three specimens shows the shape of an upward convex function curve. The creep strain curve of specimen S12 is an upward convex curve, while the creep strain curves of specimens S22 and S32 are concave curves.

For specimen S12, the proportion of elastic strain within the total strain was $38.1 \% \sim 42.3 \%$, and the overall change range was small, as shown in Figure 7(a). For specimen S22, the proportion of elastic strain within the total strain decreased overall, while the proportion of creep strain increased, from $23.5 \%$ to $44.1 \%$, as shown in Figure 7 (b). For specimen S32, the proportion of elastic strain in the total strain decreased from $83.7 \%$ to $54.1 \%$, showing a large decrease, while the proportion of creep strain increased greatly, with the proportion of creep strain accounting for $16.3 \% \sim 45.9 \%$, as shown in Figure 7 (c). When comparing the creep strain variation characteristics of the three specimens, it was found that, with the increase of osmotic pressure, the proportion of creep strain in the total strain gradually increased, while the proportion of corresponding elastic strain gradually reduced.

3.3. Electrochemical Test. The seven conducted electrochemical tests correspond to $A \sim G$ in Figures $8-10$ in a 


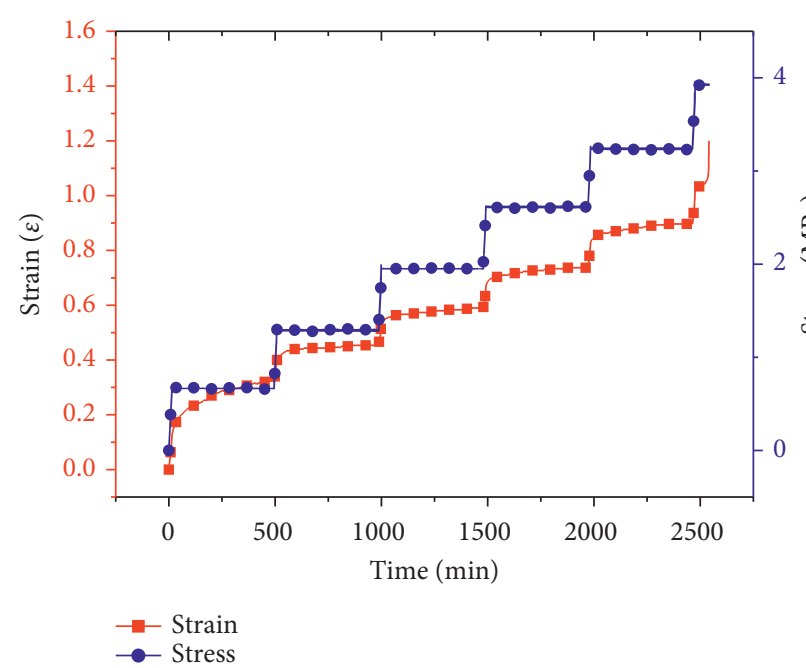

(a)

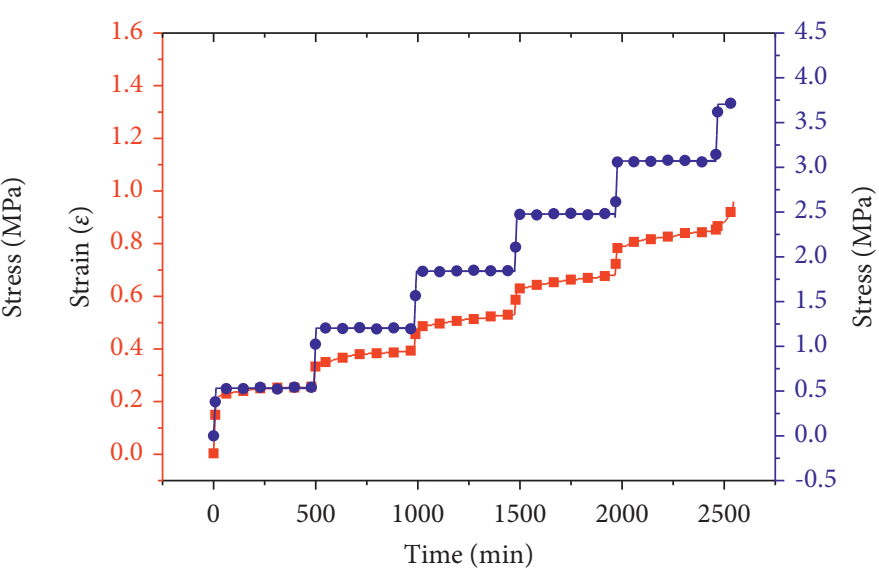

- Strain - - Stress

(b)

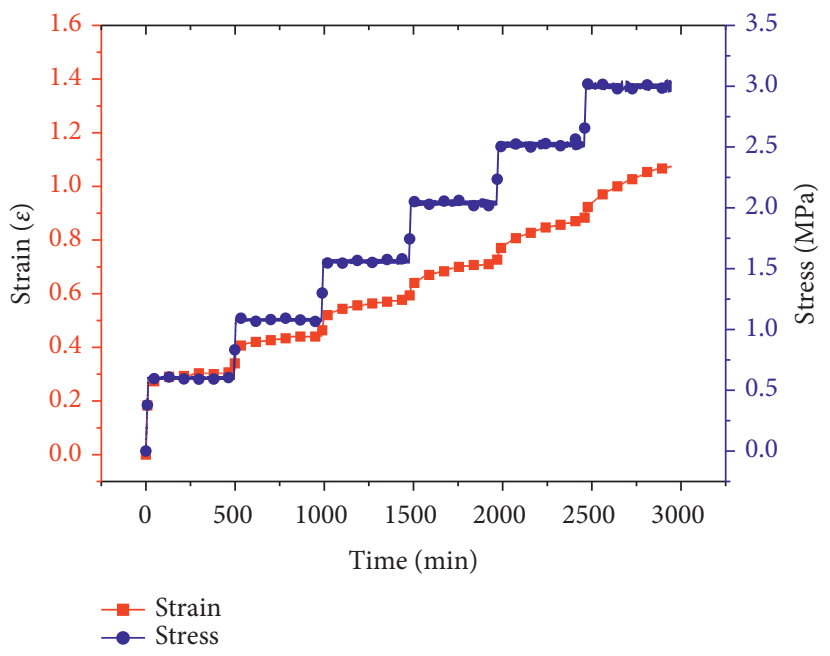

(c)

FIGURE 4: Change process of stress and strain with time: (a) S12; (b) S22; (c) S32.

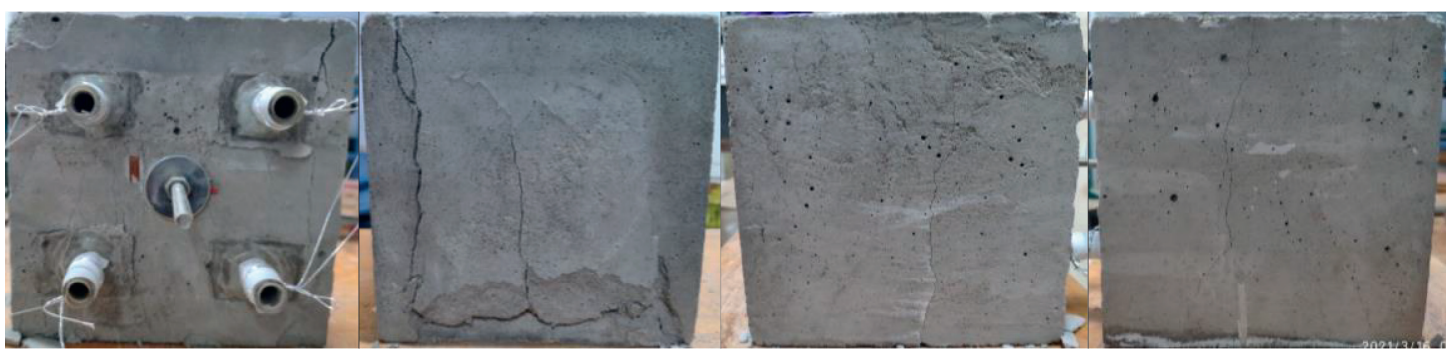

(a)

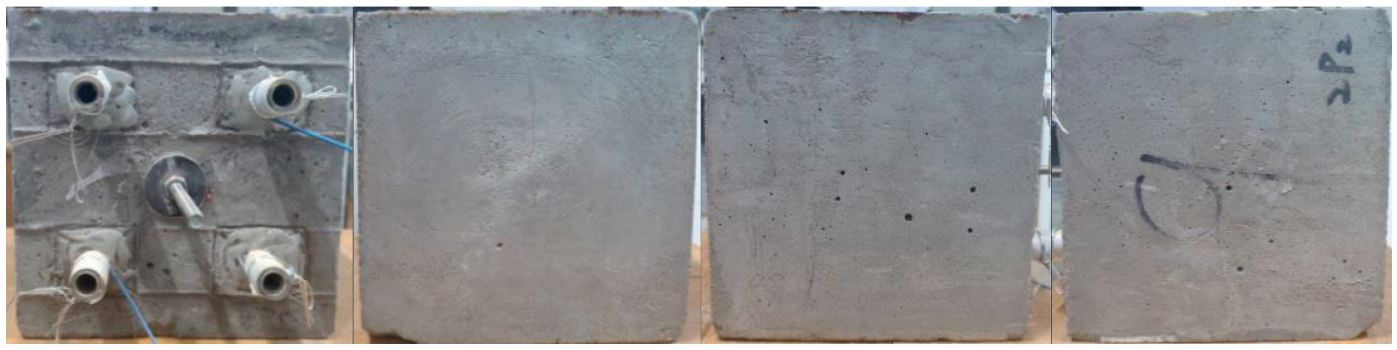

(b)

FIgURE 5: Continued. 


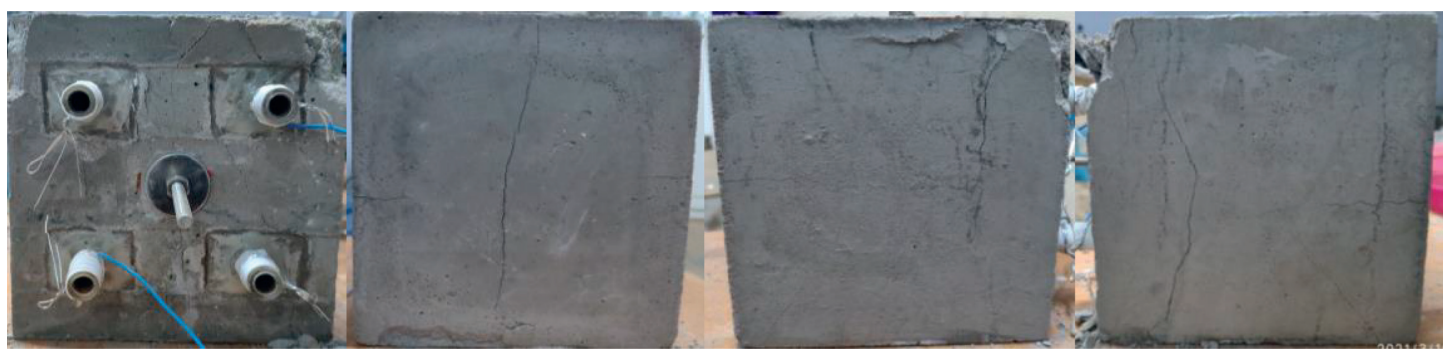

(c)

FIGURE 5: Failure of specimens after multistage loading: (a) S12; (b) S22; (c) S32.

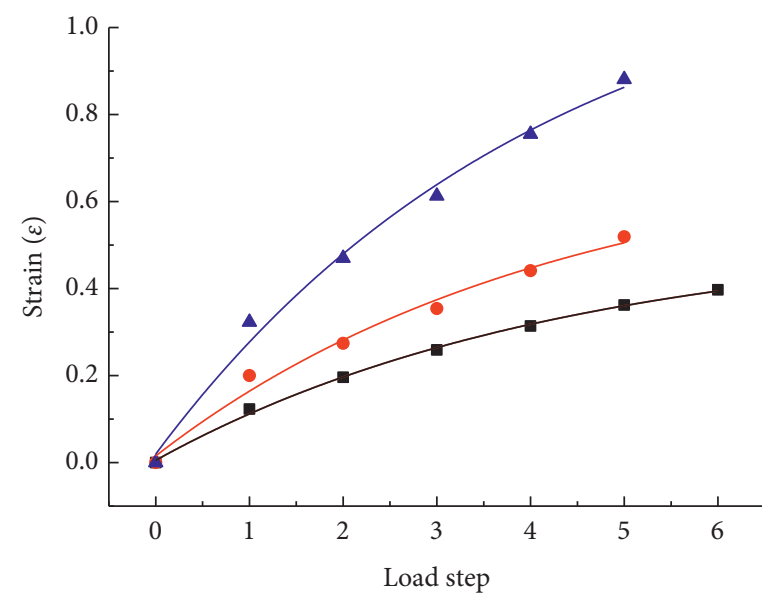

- Elastic strain - Creep strain

^ Total strain

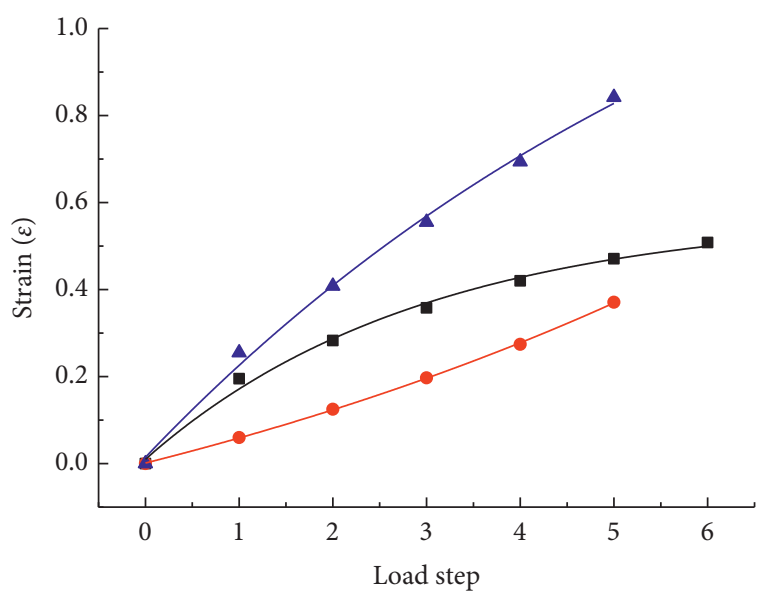

- Elastic strain

- Creep strain

$\Delta$ Total strain

(b)

(a)

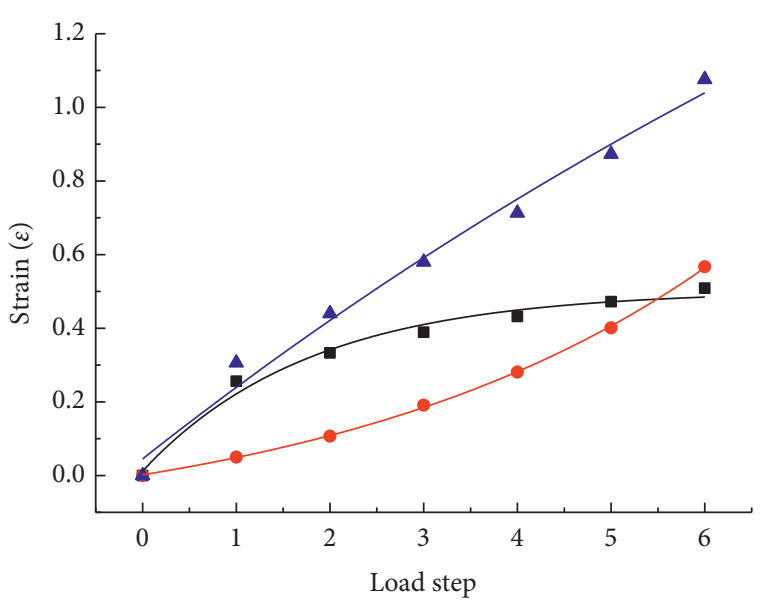

- Elastic strain

- Creep strain

A Total strain

(c)

FIGURE 6: Elastic strain, creep strain, and total strain of the specimens: (a) S12; (b) S22; (c) S32. 


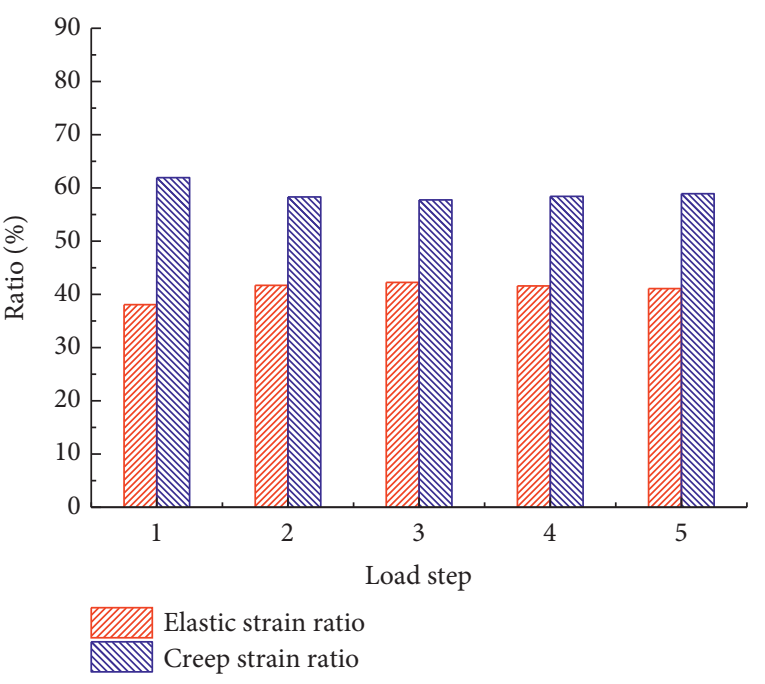

(a)

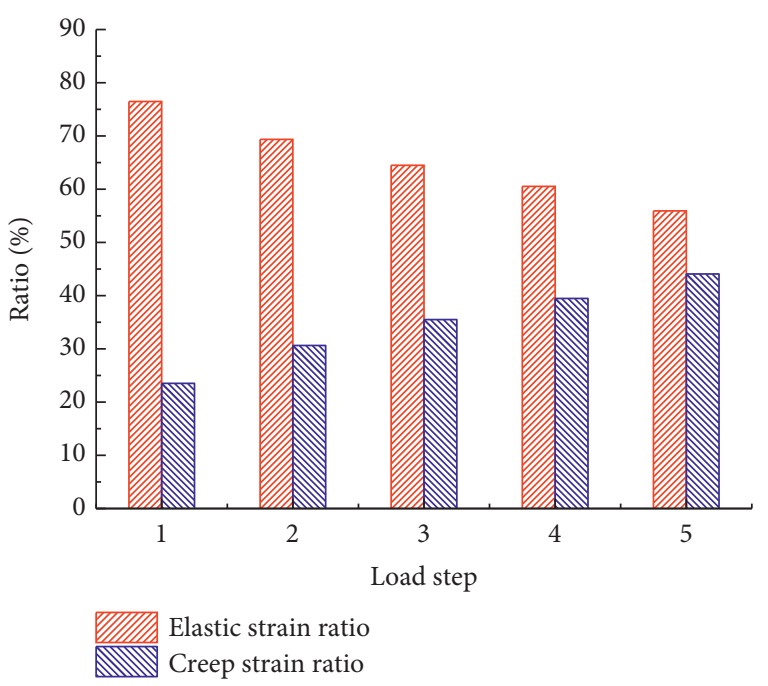

(b)

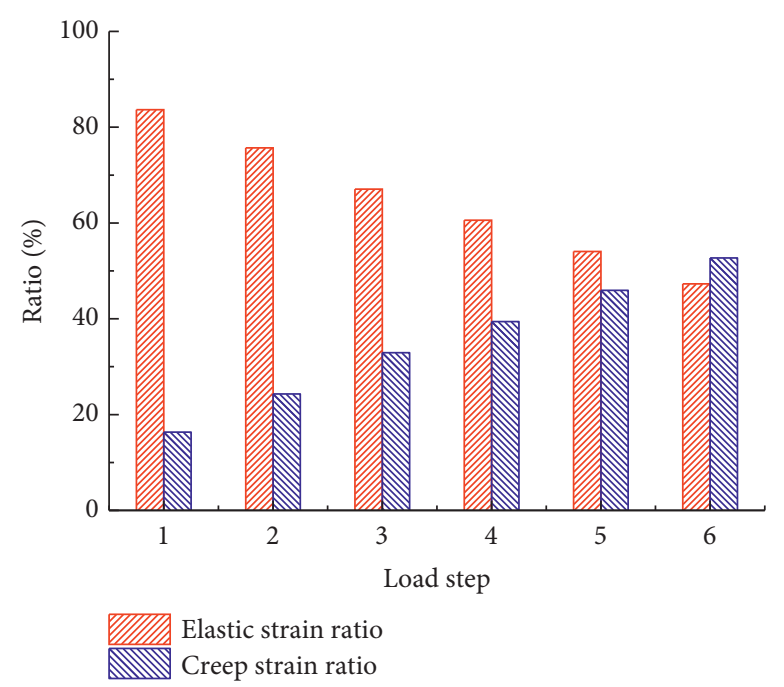

(c)

FIGURE 7: The proportion of elastic strain and creep strain within the total strain of specimens: (a) S12; (b) S22; (c) S32.

chronological order. Curve A is the test result of each specimen before loading, and curves $B \sim G$ are the test results 10 minutes before the end of the $1^{\text {st }}$ to $6^{\text {th }}$ loading stage of each specimen. If the test was completed in advance, an electrochemical detection would be carried out at the end of the test. It can be seen from Figure 8 that the electrochemical curves obtained at different times of the same specimen are different. The reason for this was that, under the combined action of load and osmotic pressure, the internal pores and electrical conductivity of the specimen also changed continuously. For specimen S21, except for the Bode impedance curve obtained from the second measurement, the other six curves generally show a downward trend. For specimen S22, the Bode impedance curves obtained from seven measurements generally show a downward trend. The impedance values $Z$ obtained from the seventh measurement of specimen S21 and specimen S22 were smaller. This indicates that their impedance values were decreasing with the progress of the test. When $\ln F<\ln 4.99$, specimen S32's five Bode impedance curves, except curves $D$ and $F$, show a strong jump. When $\ln F \geq \ln 4.99$, specimen S32's seven Bode impedance curves show a downward trend as a whole. The results indicate that the relationship between the growth of pores in the specimen and the influence of pressure 


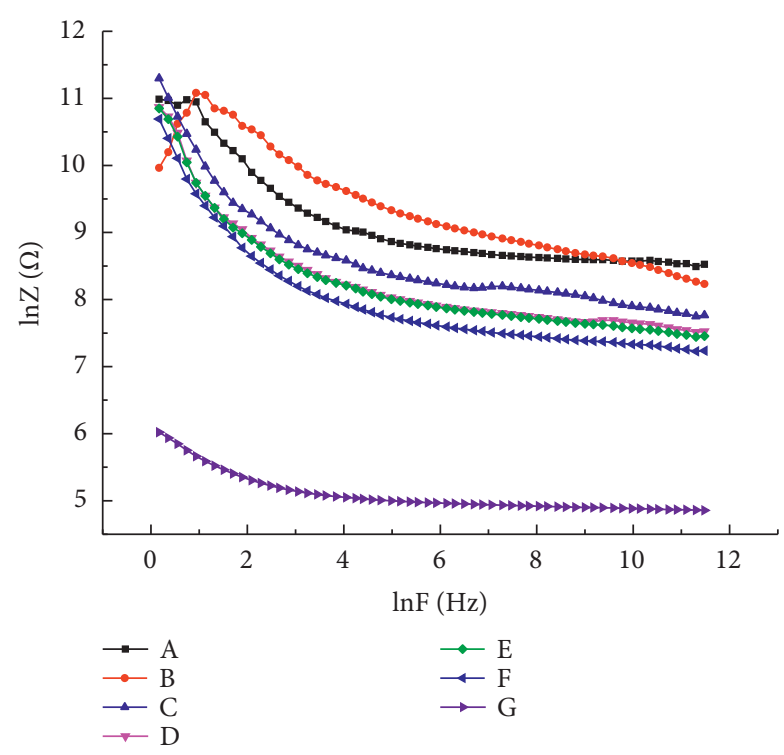

(a)
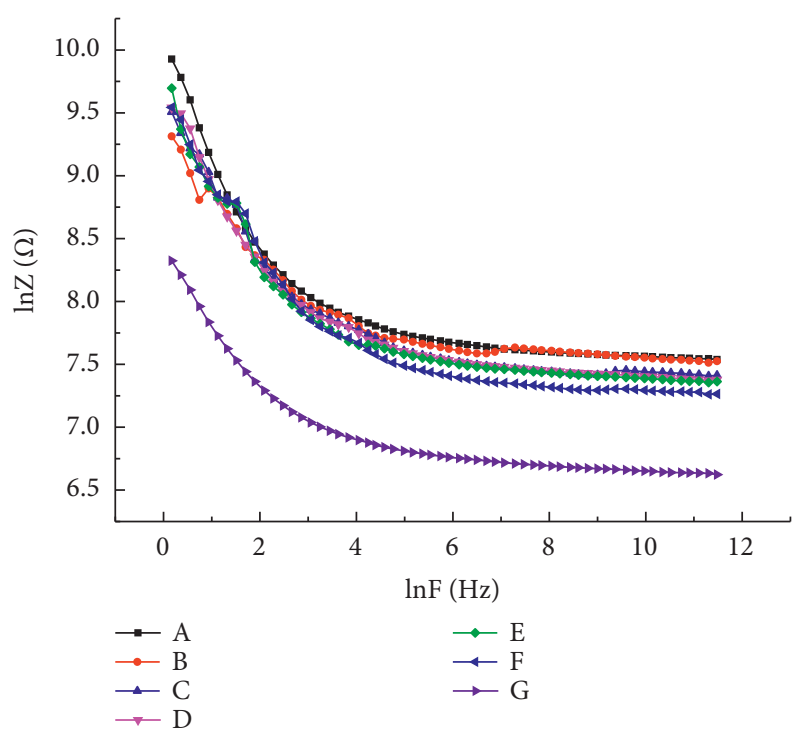

(b)

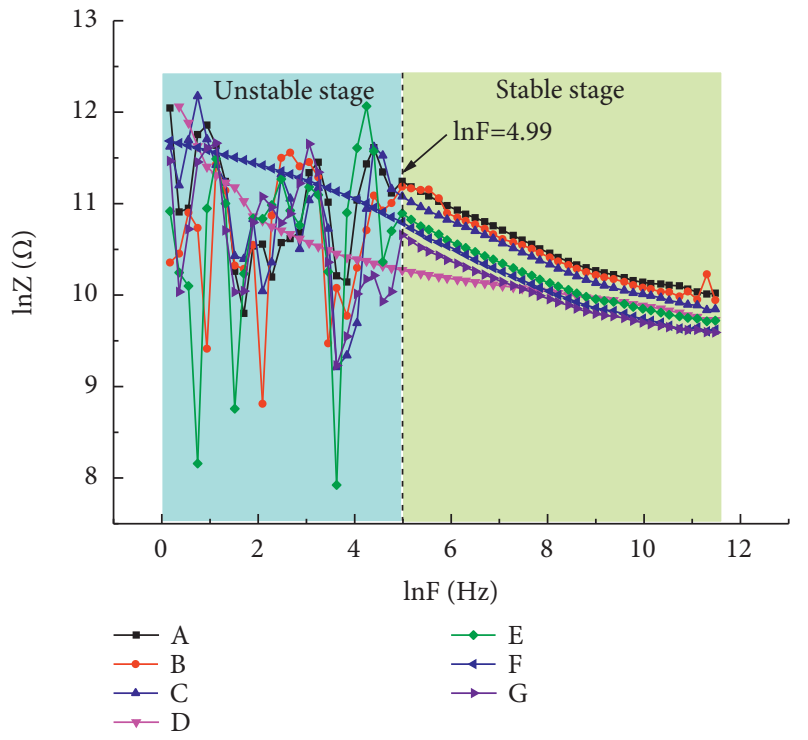

(c)

FIGURE 8: Bode impedance diagram of specimens under osmotic pressure: (a) S12; (b) S22; (c) S32.

seepage was in a nonequilibrium state in the low-frequency band. In the high-frequency band, their effects on Bode impedance gradually returned to stability.

As seen from Figure 9, the phase angle varied with the detection time and detection frequency. There was no obvious regularity in the phase angle of the sample in the low-frequency band. In particular, for specimen S32, the frequency range was $\ln F \in(0, \ln 4.99)$. During the second stage loading measurement, the phase angle curves $\mathrm{B}$ of specimen S12 and specimen S22 changed greatly in the low-frequency band. The change of specimen S32 phase angle low frequency under various loading conditions was in an unstable stage. After entering the high-frequency band, the change in phase angle of specimen S32 entered the stable stage. With the increase of detection frequency, the phase angle also increased with the increase of frequency. In the high-frequency band, the phase angle of each detection time point was relatively similar. In particular, the phase angles of specimen S22 and specimen S32 were the closest. 


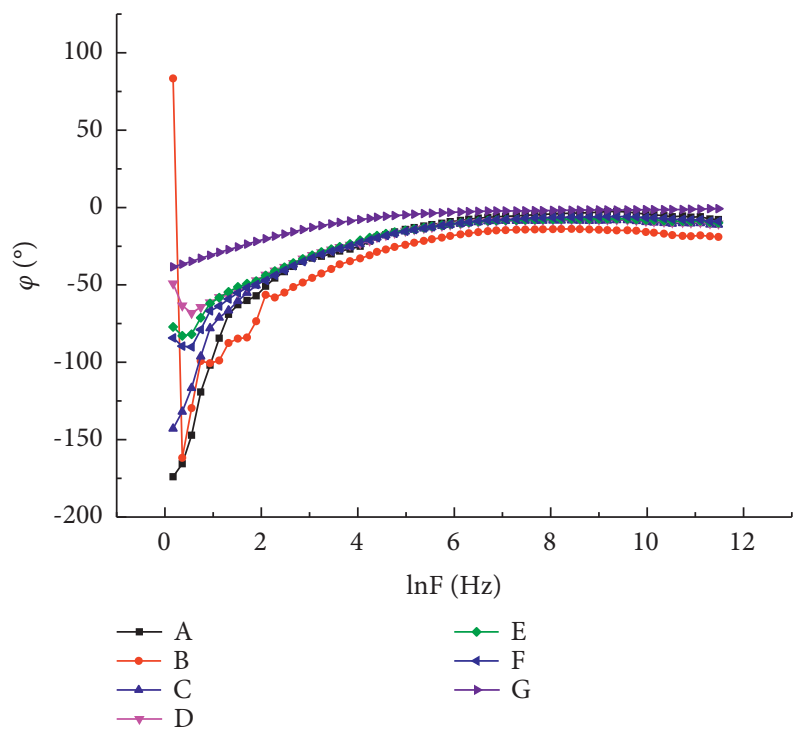

(a)

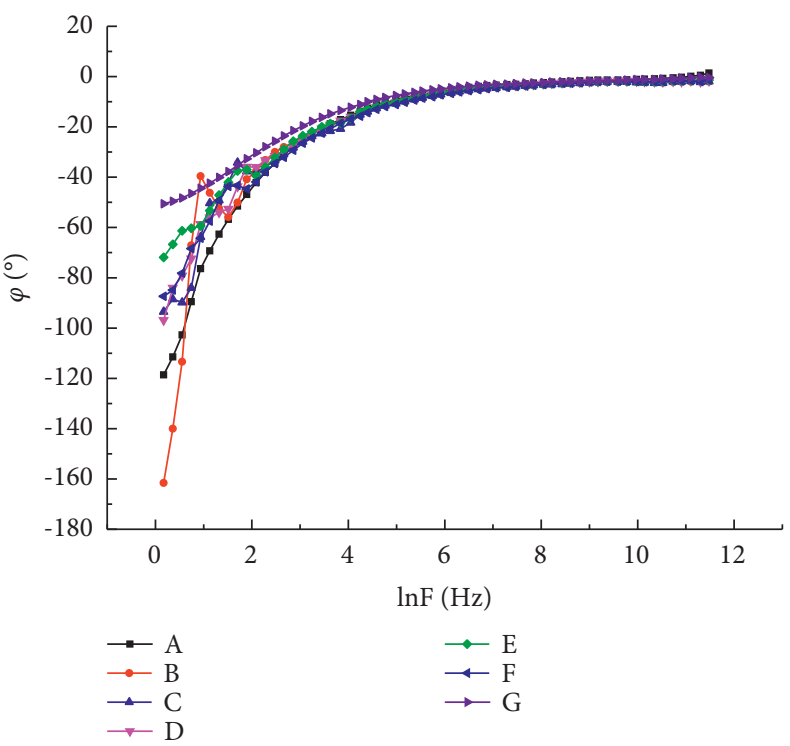

(b)

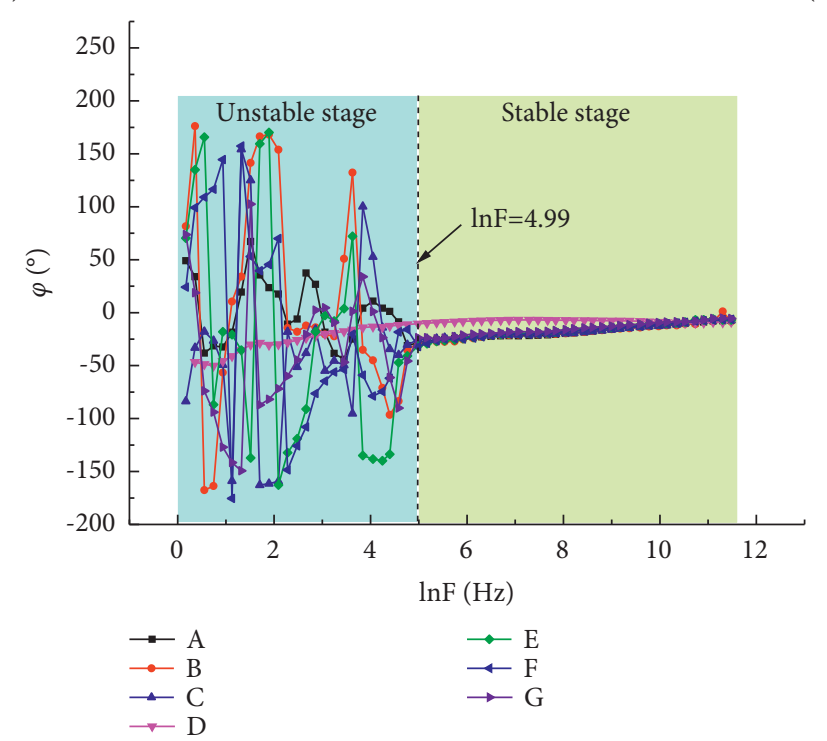

(c)

Figure 9: Bode phase diagram of specimens under osmotic pressure: (a) S12; (b) S22; (c) S32.

The Nyquist curves of specimens S12, S22, and S32 under osmotic pressure are shown in Figure 10. For the three specimens, with the increase of stress and the extension of loading time, the seven curves $A \sim G$ gradually approach the frequency axis in the coordinate system, and the length of the curves gradually becomes shorter. In particular, the length of the seventh curve $G$ of specimen S12 is more obviously shortened, which is related to the failure of specimen S12 as a whole and the penetration of cracks in the specimen. Compared with the first six Nyquist curves of specimen S22, the seventh curve $G$ is somewhat scattered, which is also related to the failure of the specimen. The overall distribution of the seven Nyquist curves is relatively concentrated mainly because specimen S32 was not completely damaged. 


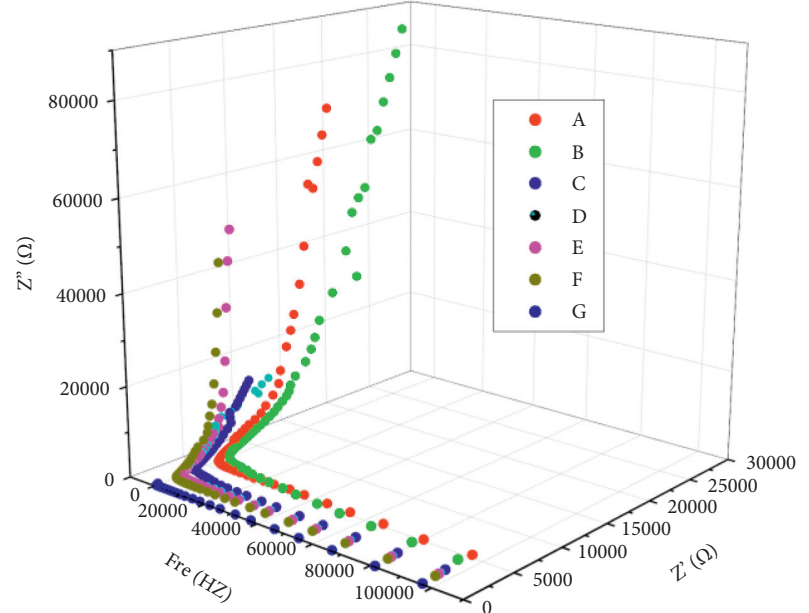

(a)

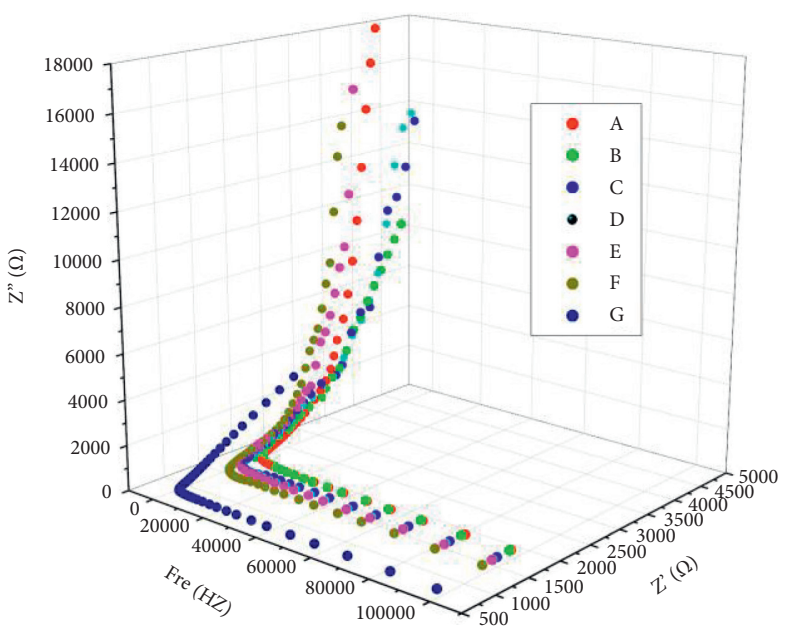

(b)

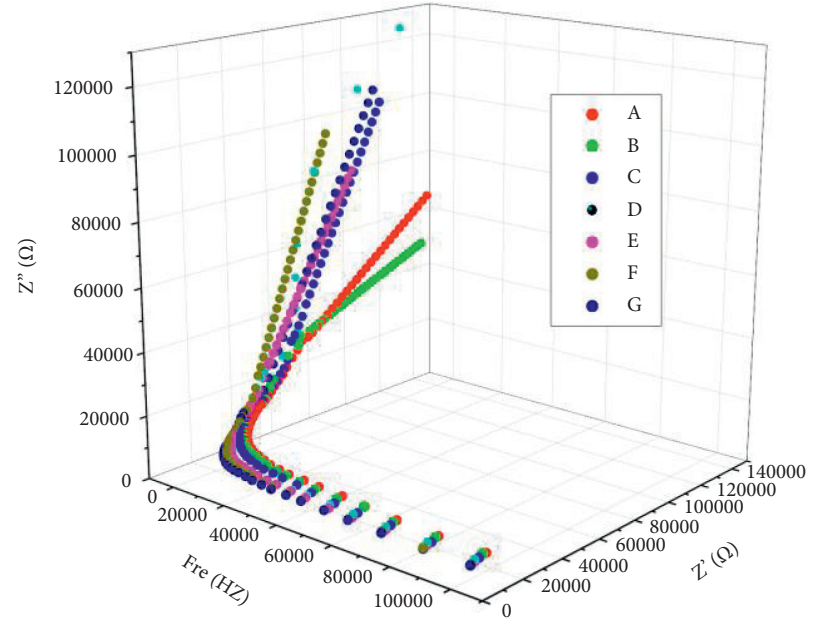

(c)

Figure 10: Nyquist curves of specimens under osmotic pressure: (a) S12; (b) S22; (c) S32.

\section{Conclusions}

This work investigated the strain characteristics and electrochemical characteristics of anchor bolt specimens under multistage loading and osmotic pressure. The main conclusions are as follows:

(1) The osmotic pressure has an obvious effect on reducing the uniaxial compressive strength of the specimen. The uniaxial compression test results show that the uniaxial compressive strength of the specimens under the osmotic pressures of $0.05 \mathrm{MPa}$, $0.10 \mathrm{MPa}$, and $0.15 \mathrm{MPa}$ was $4.4 \mathrm{MPa}, 4.0 \mathrm{MPa}$, and 3.1 $\mathrm{MPa}$, respectively. Larger osmotic pressure is likely to lead to more serious damage.

(2) When the specimen is subjected to multistage loading, the osmotic pressure will increase the creep deformation ratio of the specimen. Osmotic pressure also changes the total strain deformation, elastic deformation, and creep deformation of the specimen. The specimen produces cracks that are consistent with the load direction.
(3) Under different osmotic pressures, the electrochemical impedance spectra measured at each loading level show variations. In particular, the Bode diagram and Nyquist diagram measured in the seventh stage during the failure of specimens S11 and S12 are more different from those measured in the first six stages.

\section{Data Availability}

Data used in the study are contained within the article.

\section{Conflicts of Interest}

The authors declare that there are no conflicts of interest.

\section{Authors' Contributions}

J. H. and H. W. designed the research methods. D. L. tested the specimens. G. S. analyzed the data and wrote the manuscript. 


\section{Acknowledgments}

The research work has been greatly supported by the Zhongyuan University of Technology and its staff in terms of test instruments and test methods. The funding for this investigation was provided by the National Natural Science Foundation of China (no. 51574296), China Scholarship Council (no. 202008410379), and the Young Backbone Teachers of Zhongyuan University of Technology (no. 2018XQG14). The authors gratefully acknowledge the relevant organizations.

\section{References}

[1] H. Dong, X. Zhu, X. Jiang, L. Chen, and Q.-F. Gao, "Structural characteristics of soil-rock mixtures based on electrochemical impedance spectroscopy," Catena, vol. 207, Article ID 105579, 2021.

[2] B. He, Y. Wang, R. Xie, P. Han, and X. Bai, "A method for evaluating corrosion of contaminated soil-electrochemical impedance spectroscopy (EIS) method," Proceedings of the 8th International Congress on Environmental Geotechnics, vol. 1, 2019.

[3] J. Zhu, X. Wang, C. Li, and B. Lu, "Corrosion damage behavior of prestressed rock bolts under aggressive environment," Ksce Journal of Civil Engineering, vol. 23, no. 7, pp. 3135-3145, 2019.

[4] N. Mundhenk, K. G. Knauss, S. R. S. Bandaru, R. Wonneberger, and T. M. Devine, "Corrosion of carbon steel and the passivating properties of corrosion films formed under high-PT geothermal conditions," The Science of the Total Environment, vol. 677, pp. 307-314, 2019.

[5] Y. D. Blanco, E. C. M. Campos, C. I. R. Valdés, and J. U. Chavarín, "Effect of recycled PET (polyethylene terephthalate) on the electrochemical properties of rebar in concrete," International Journal of Civil Engineering, vol. 18, no. 5, pp. 487-500, 2020.

[6] X. R. Nóvoa, "Electrochemical aspects of the steel-concrete system. A review," Journal of Solid State Electrochemistry, vol. 20, no. 8, pp. 2113-2125, 2016.

[7] T. Nishimura, "Electrochemical behavior of steel in concrete under wet and dry condition with $\mathrm{NaCl}$ solution," Journal of Materials Engineering and Performance, vol. 28, no. 3, pp. 1500-1508, 2019.

[8] D. V. P. Tran, P. Sancharoen, P. Klomjit, and S. Tangtermsirikul, "Electrochemical compatibility of patching repaired reinforced concrete: experimental and numerical approach," Journal of Adhesion Science and Technology, vol. 34 , no. 8, pp. 828-848, 2020.

[9] S. O. Engblom, J. C. Myland, K. B. Oldham, A. L. Taylor, and W. C. Topic, "Electrochemical detection of large channels in porous rocks," Journal of Applied Electrochemistry, vol. 33, no. 1, pp. 51-59, 2003.

[10] M. Najimi, J. Sobhani, and A. Pourkhorshidi, "Electrochemical impedance behavior of concrete containing natural zeolite and copper slag," Asian Journal of Civil Engineering, vol. 20, no. 6, pp. 847-855, 2019.

[11] K. Berrami, A. Ech-chebab, M. Galai et al., "Evaluation of fly ash effect on the durability of prestressed concrete cylindrical pipe in aggressive soil by electrochemical method," Chemical Data Collections, vol. 32, Article ID 100656, 2021.

[12] M. G. Sohail, R. Kahraman, N. A. Alnuaimi et al., "Electrochemical behavior of mild and corrosion resistant concrete reinforcing steels," Construction and Building Materials, vol. 232, Article ID 117205, 2020.

[13] W. Nguyen, J. F. Duncan, T. M. Devine, and C. P. Ostertag, "Electrochemical polarization and impedance of reinforced concrete and hybrid fiber-reinforced concrete under cracked matrix conditions," Electrochimica Acta, vol. 271, pp. 319336, 2018.

[14] J. Eid, H. Takenouti, B. Ait Saadi, and S. Taibi, "Electrochemical studies of steel rebar corrosion in clay: application to a raw earth concrete," Corrosion Science, vol. 168, Article ID 108556, 2020.

[15] K. Cabrera-Luna, E. E. Maldonado-Bandala, D. NievesMendoza, P. Castro-Borges, and J. I. E. García, "Novel low emissions supersulfated cements of pumice in concrete; mechanical and electrochemical characterization," Journal of Cleaner Production, vol. 272, Article ID 122520, 2020.

[16] H. M. Park and S. W. Park, "Evaluation of corrosion effects on permanent ground anchors," Journal of the KGS, vol. 20, no. 2, pp. 27-36, 2004.

[17] Z. Wu, H. Yu, H. Ma, B. Da, and Y. Tan, "Rebar corrosion behavior of coral aggregate seawater concrete by electrochemical techniques," Anti-corrosion Methods \& Materials, vol. 67, no. 1, pp. 59-72, 2020.

[18] P. Shuquan, W. Fan, and F. Ling, "Study on electrochemical impedance response of sulfate saline soil," International Journal of Electrochemical Science, vol. 14, pp. 8611-8623, 2019.

[19] F. Jiang, J. Gong, J. Zhu, and H. Wang, "Study on the concrete in chloride environment based on electrochemical impedance spectroscopy," International Journal of Pattern Recognition and Artificial Intelligence, vol. 34, no. 6, Article ID 2059017, 2020.

[20] S. Robuschi, K. Lundgren, I. Fernandez, and M. Flansbjer, "Anchorage of naturally corroded, plain reinforcement bars in flexural members," Materials and Structures, vol. 53, no. 2, 2020.

[21] G. Sun, J. Hu, H. Wang, and P. Li, "Experimental study on the deformation and failure characteristics of anchor under graded loading and corrosion," Advances in Materials Science and Engineering, vol. 2021, Article ID 8701180, 11 pages, 2021.

[22] X. Li, G. Yi, W. Wang, J. Sun, and Y. Li, "Research and application of RBF neural network-based osmotic pressure forecast model for concrete-faced rockfill dam," IOP Conference Series. Earth and Environmental Science, vol. 189, no. 2, Article ID 22018, 2018.

[23] C. Zhang, Y. Wang, and T. Jiang, "The propagation mechanism of an oblique straight crack in a rock sample and the effect of osmotic pressure under in-plane biaxial compression," Arabian Journal of Geosciences, vol. 13, no. 15, pp. 1-15, 2020.

[24] J. Feng and G. Zhang, "Study on soil water and suction stress characteristics for unsaturated clay soil of airport engineering based on laboratory tests," Geofluids, vol. 2021, Article ID 5233045, 8 pages, 2021

[25] X. Shi, H. Jing, W. Chen, Y. Gao, and Z. Zhao, "Investigation on the creep failure mechanism of sandy mudstone based on micromesoscopic mechanics," Geofluids, vol. 2021, Article ID 5550733, 19 pages, 2021.

[26] X. Huang, Y. Long, Y. Wang, and M. Yue, "Experimental research of the influence of microfracture morphology on permeability of shale rock," Geofluids, vol. 2021, Article ID 5587817, 7 pages, 2021.

[27] M. Gao and Y. Liu, "Experimental study on the influence of moisture content on the mechanical properties of coal," Geofluids, vol. 2021, Article ID 6007410, 9 pages, 2021. 
[28] S. Peng, K. Zhang, L. Fan, J. Kang, K. Peng, and F. Wang, "Permeability reduction and electrochemical impedance of fractured rock grouted by microbial-induced calcite precipitation," Geofluids, vol. 2020, Article ID 8876400, 11 pages, 2020.

[29] S.-Q. Yang, M. Chen, Y.-H. Huang, H.-W. Jing, and P. G. Ranjith, "An experimental study on fracture evolution mechanism of a non-persistent jointed rock mass with various anchorage effects by DSCM, AE and X-ray CT observations," International Journal of Rock Mechanics and Mining Sciences, vol. 134, Article ID 104469, 2020.

[30] H. Jing, J. Wu, Q. Yin, and K. Wang, "Deformation and failure characteristics of anchorage structure of surrounding rock in deep roadway," International Journal of Mining Science and Technology, vol. 30, no. 5, pp. 593-604, 2020.

[31] L. Dai, Y. Chen, L. Wang, and Y. Ma, "Secondary anchorage and residual prestressing force in locally corroded PT beams after strand fracture," Construction and Building Materials, vol. 275, Article ID 122137, 2021.

[32] Q. Wang, H. Zhu, B. Zhang, Y. Tong, F. Teng, and W. Su, "Anchorage systems for reinforced concrete structures strengthened with fiber-reinforced polymer composites: stateof-the-art review," Journal of Reinforced Plastics and Composites, vol. 39, no. 9-10, pp. 327-344, 2020.

[33] Z. Zhao, Q. Ma, Y. Tan, and X. Gao, "Load transfer mechanism and reinforcement effect of segmentally yieldable anchorage in weakly consolidated soft rock," Simulation, vol. 95, no. 1, pp. 83-96, 2019.

[34] S. Porcarelli, D. Shedde, Z. Wang, J. M. Ingham, I. Giongo, and D. Dizhur, "Tension and shear anchorage systems for limestone structures," Construction and Building Materials, vol. 272, Article ID 121616, 2021. 